\section{CARACTERÍSTICAS DE PLÁNTULAS EN FAMILIAS DERIVADAS DE UNA POBLACIÓN DE MÁIZ POLIEMBRIÓNICO}

\author{
SEEDLING TRAITS IN MAIZE FAMILIES \\ DERIVED FROM A POLYEMBRINIC \\ POPULATION
}

\author{
Noé Musito Ramírez*, José Espinoza Velázquez, \\ Víctor M. González Vázquez, José E. Gallegos \\ Solórzano y Humberto de León Castillo ${ }^{1}$
}

\footnotetext{
${ }^{1}$ Instituto Mexicano del Maíz "Dr. Mario E. Castro Gil”, Universidad Autónoma Agraria Antonio Narro. 25315, Buenavista, Saltillo, Coahuila, México. Tel. 01 (844) 411-0221.

* Autor para correspondencia (mussitto@gmail.com)
}

\section{RESUMEN}

La poliembrionía en maíz (Zea mays L.) es un carácter genético que se caracteriza por producir semilla prolífica y granos con alta calidad nutritiva. En este trabajo se estudió la germinación, frecuencia poliembriónica y anormalidad en plántulas de 15 d de edad, así mismo, se determinó el efecto del sentido de cruza al formar familias de hermanos completos sobre estas variables. Las familias provenientes de tres tipos de familias; (líneas $\mathrm{S}_{1}$; hermanos completos $\mathrm{HC}$; y medios hermanos, $\mathrm{MH}$ ) se derivaron de una población poliembriónica de porte normal, denominada UA-IMM-NAP, durante el ciclo $P-V / 2005$ en Saltillo, Coahuila, México. Las familias $\left(403 S_{1}, 330\right.$ HC y 169 MH) se sembraron en cajas de germinación con 30 semillas por caja, y a los $15 \mathrm{~d}$ después de la siembra se hicieron las evaluaciones. El diseño experimental fue completamente al azar, con datos desbalanceados, con un modelo de efectos aleatorios. Los resultados mostraron que el grupo de MH presentó superioridad $(\mathrm{P}<$ $0.01)$ sobre los otros dos, en germinación $(95 \%)$, poliembrionía (63 \%) y normalidad de plántula $(90 \%)$. La endogamia de las líneas $S_{1}$ redujo los valores de las características evaluadas y no produjo incremento en poliembrionía, pero permitió ubicar familias con mayor carga de genes deletéreos. Al comparar cruzas directas vs. recíprocas de los $\mathrm{HC}$, se detectaron diferencias $(\mathrm{P}<\mathbf{0 . 0 5})$ en poliembrionía, con $64 \%$ para cruzas directas y $56 \%$ para las recíprocas.

Palabras clave: Zea mays, poliembrionía, selección familial.

\section{SUMMARY}

The heritable trait polyembryony in maize (Zea mays L.) is suitable for special breeding purposes because of its effect on seed prolificacy and grain nutrimental quality. This work reports the performance of $15 \mathrm{~d}$ old seedlings on germination, polyembryony, seedling abnormalities and the effect of crossing direction in the full sib family group. Three types of family structures (selfed, $S_{1}$; half sibs, HS; and full sibs, FS) were derived from a polyembryonic maize population named UA-IMM-NAP during the Spring-Summer 2005 in Saltillo, Coahuila, México. The families $\left(403 \mathrm{~S}_{1}, 330 \mathrm{FS}\right.$ and 169 , HS) were represented by a random sample of 30 seeds which were sown in germination boxes, and evaluated $15 \mathrm{~d}$ afterwards. The experiment was done using a completely randomized design with unbalanced data, and assuming a random model regarding the family genotypes. Results showed that the HS group was the highest $(\mathrm{P}<$ $0.01)$ in germination $(95 \%)$, polyembryony $(63 \%)$ and seedling normality $(90 \%)$. The inbreeding of $S_{1}$ depressed the average values and did not produce any increase in polyembryony frequency; however, it was effective to uncover genotypes with most deleterious genes. When FS direct vs. reciprocal crossings were compared, differences $(P<0.05)$ were detected in polyembryony, with $64 \%$ for direct crosses and $56 \%$ for reciprocal crosses.

Index words: Zea mays, polyembryony, family selection.

\section{INTRODUCCIÓN}

Los programas de mejoramiento genético dirigen la selección hacia los individuos cuyos genes expresen idealmente alguna característica de interés. La condición gemelar o de poliembrionía (PE) en semillas de maíz (Zea mays) es una característica natural que puede utilizarse como vía alterna en el diseño de estrategias genotécnicas, pues además del potencial de rendimiento de grano se puede seleccionar por su valor nutritivo, $i$. e., cantidad de aceite y calidad de proteína (Espinoza et al., 1998).

Las características favorables de la poliembrionía, son: 1) Prolificación de la semilla al dar origen simultáneo a dos o más plantas completas funcionales; 2) Capacidad competitiva de las plantas hermanas in situ y sus vecinas; y 3) Calidad físico-química sobresaliente del grano. Esta calidad nutrimental ha sido corroborada (Valdez

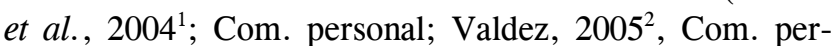
sonal) al resaltar la superioridad de los maíces PE en grasa y lisina, con 33 y $100 \%$, respectivamente, comparada con los niveles de un maíz común.

La manifestación del carácter puede originarse por genes de efectos mayores (naturaleza monogénica) o poligenes (naturaleza cuantitativa). En el primer tipo destaca el denominado gen ig, el cual en condición homocigótica recesiva genera semillas con embrión monoploide en $3 \%$ de los casos y poliembrionía en $6 \%$ (Hallauer y Miranda, 1988), o por un gen simple de herencia recesiva, no identificado, como lo señala Pilu (2000). Sin embargo, Pesev et al. (1976), Rodríguez y Castro, $\left(1978^{3}\right.$; Com. personal)

\footnotetext{
${ }^{1}$ Valdez L, J Espinoza, A F Aguilera, M L Reyes V (2004) Fatty acids in polyembryonic maize. Abstract. The International Food Technologist, 2004 Annual Meeting. July 12-16, 2004. Las Vegas, Nevada.

${ }^{2}$ Valdez L L (2005) Ganancia en calidad nutrimental del grano como respuesta asociada a la selección para poliembrionía en maíz. Tesis de maestría en Fitomejoramiento. Universidad Autónoma Agraria "Antonio Narro". Buenavista, Saltillo, Coahuila, México. 58 p.

${ }^{3}$ Rodríguez H S, M Castro G (1978) Estudio sobre herencia de semillas con doble embrión. Avances de Investigación 1978. Universidad Autónoma Agraria “Antonio Narro”. Buenavista, Saltillo, Coahuila, México. p:19.
} 
y Castro (1979 ${ }^{4}$; Com. personal) consideran que la herencia del carácter PE es cuantitativa; este último autor señala una heredabilidad de $65 \%$, por lo que prácticamente cualquier método de selección funcionará de manera eficiente para modificar la frecuencia del carácter en la población de interés.

Los resultados de selección en los maíces poliembriónicos, denominados poblaciones UA-IMM-BAP y UAIMM-NAP, generados en la Universidad Autónoma Agraria "Antonio Narro" (UAAAN) en el periodo 1994-2005, indican una acumulación de 15 y $20 \%$ de la característica PE, respectivamente (Espinoza y Vega, 2000 ; Com. personal), que representan ganancias por ciclo entre 1 y $2 \%$ lo que de algún modo apoya la naturaleza cuantitativa del carácter. En éste, como en otros casos similares (Livini et al., 1992; Weyhrich et al., 1998), la aplicación de métodos de selección recurrente en familias $S_{1}$ y hermanos completos (HC) es apropiada para mejorar variedades, al incrementar la frecuencia de la poliembrionía, mejorar la germinación y reducir la frecuencia de plantas anormales.

En este trabajo se aborda el comportamiento de plántulas de tres tipos de familias: líneas $S_{1}$, medios hermanos (MH) y HC, así como el efecto de cruzas directas y recíprocas al generar familias de $\mathrm{HC}$, obtenidas a partir de una población amplia de maíz que incluye el carácter poliembrionía en una frecuencia de $54 \%$. Los objetivos de este estudio fueron evaluar la germinación y frecuencia poliembriónica en los tres tipos de familias, y analizar el efecto del sentido de las cruzas de hermanos completos sobre la frecuencia poliembriónica.

\section{MATERIALES Y MÉTODOS}

Los genotipos correspondientes a los tres tipos de familias (líneas $\mathrm{S}_{1}, \mathrm{HC}$ y $\mathrm{MH}$ ) provinieron de una población poliembriónica denominada UA-IMM-NAP (NAP, de porte normal y alta poliembrionía. Sus características de interés son: $75 \%$ de germinación (GE), $54 \%$ de PE y 15 $\%$ de plantas anormales (AN), exhibidas un mes después de la siembra en campo durante el ciclo primavera-verano $(\mathrm{P}-\mathrm{V}) / 2005$. La siembra fue en marzo del 2005 en una superficie de $1000 \mathrm{~m}^{2}$ con riego; se cosechó en agosto del mismo año. La densidad de siembra inicial fue de 113600 semillas por hectárea (una semilla por golpe) con la finalidad de forzar y favorecer la competitividad durante la

\footnotetext{
${ }^{4}$ Castro G M 1979 (1979) Estudios sobre herencia y valor nutritivo de semillas con doble embrión. In: Avances de investigación. Sección Maíz. Universidad Autónoma Agraria Antonio Narro. pp:3-4. Buenavista, Saltillo, Coahuila, México.

${ }^{5}$ Espinoza J, M C Vega (2000) Maíces de alta frecuencia poliembriónica. In: Memoria del XVIII Congreso Nacional de SOMEFI. Irapuato, Guanajuato, México. 15 al 20 de octubre, 2000. p:4.
}

emergencia y establecimiento de plantas poliembriónicas; la fertilización inicial fue $120 \mathrm{~N}-110 \mathrm{P}-100 \mathrm{~K}$, y a los $40 \mathrm{~d}$ se aplicó una segunda fertilización (60N-00P-00K), y se redujo la densidad de población aproximadamente a 62000 plantas por hectárea, mediante la eliminación de plantas individuales y poliembriónicas con características no deseables.

Las familias $\mathrm{S}_{1}, \mathrm{MH}$ y $\mathrm{HC}$ se generaron durante el ciclo primavera-verano 2005 , en Saltillo, Coahuila $\left(25^{\circ} 21^{\prime}\right.$ $\left.\mathrm{LN}, 101^{\circ} 02^{\prime} \mathrm{LO}, 1758 \mathrm{msnm}\right)$. Durante el proceso de formación de familias generalmente se usaron "matas" para identificar los casos de dos o más plantas que proceden de la misma semilla; esto permitió hacer en una planta una polinización de tipo $\mathrm{HC}$ y una $\mathrm{S}_{1}$ en la otra, y producir 76 casos de cruzas de hermanos completos, directas y recíprocas, con sus respectivas familias $S_{1}$. Estas familias se formaron al autofecundar una planta por "mata"; las de $\mathrm{HC}$ se formaron mediante cruza fraternal planta a planta, y las de MH mediante cruzas fraternales con mezcla de polen (Cuadro 1).

Cuadro 1. Tipos de familias derivadas de una población poliembriónica de maíz, crecidas en invernadero.

\begin{tabular}{lccc}
\hline Tipos & $\begin{array}{c}\text { Núm. de } \\
\text { familias } \\
\text { por tipo }\end{array}$ & $\begin{array}{c}\text { Núm. de familias } \\
\text { HC en cruza directa } \\
\text { con sus } \\
\text { respectivas } \mathrm{S}_{1}\end{array}$ & $\begin{array}{c}\text { Núm. de familias } \\
\text { HC en cruza } \\
\text { recíproca con sus } \\
\text { respectivas } \mathrm{S}_{1}\end{array}$ \\
\hline $\mathrm{S}_{1}$ & 403 & 0 & 0 \\
$\mathrm{HC}$ & 330 & 38 & 38 \\
$\mathrm{MH}$ & 169 & 0 & 0 \\
\hline $\mathrm{S}_{1}=$ Primera autofecundación; HC $=$ Hermanos completos; $\mathrm{MH}=$ \\
Medios hermanos.
\end{tabular}

Las plántulas correspondientes a los tres tipos de familias se evaluaron bajo invernadero durante noviembre del 2005; el diseño experimental fue completamente al azar con datos desbalanceados, y se usó un modelo aleatorio con respecto a los genotipos (familias). La siembra se hizo en charolas de unicel con 200 cavidades; el sustrato de siembra fue una mezcla 2:1 de tierra de bosque y "peat moss". Se sembraron 30 semillas por familia, una por cavidad; se aplicó un riego diario con regadera manual hasta los 15 d, tiempo en que se midió las siguientes variables: germinación, mediante el número de plantas emergidas; frecuencia de plántulas poliembriónicas, en los casos con dos o más tallos; y frecuencia de plántulas anormales, identificadas por mostrar alguna malformación, se expresaron por porcentaje. Los datos se transformaron mediante arco-seno $\sqrt{\mathrm{X}}$; antes de aplicar el análisis de varianza para datos desbalanceados; se hizo el análisis con el grupo de datos completos. También se corrió un análisis de varianza con datos balanceados al tomar las 169 familias de MH como base y una muestra aleatoria de $\mathrm{HC}$ y $\mathrm{S}_{1}$ del mismo tamaño. El análisis con datos balanceados (169 por tipo de familia) se utilizó para aplicar la prueba de medias 
(Tukey, 0.05). Los análisis estadísticos se hicieron con el programa SAS (SAS Institute, 2000).

\section{RESULTADOS Y DISCUSIÓN}

El análisis de varianza detectó diferencias significativa $(\mathrm{P}<0.01)$ entre tipos de familia para las tres variables (Cuadro 2). Los coeficientes de variación (CV) observados en germinación y poliembrionía fueron aceptables, en tanto que para plantas anormales el CV fue alto.

Cuadro 2. Cuadrados medios de los análisis de varianza para las variables estudiadas.

\begin{tabular}{lcccc}
\hline FV & gl & Germinación & Poliembrionía & $\begin{array}{c}\text { Plántulas } \\
\text { anormales }\end{array}$ \\
\hline $\begin{array}{l}\text { Tipos de } \\
\text { familias }\end{array}$ & 2 & $745.2^{* *}$ & $531.5^{* *}$ & $1836.9^{* *}$ \\
Error & 878 & 78.1 & 108.2 & 112.3 \\
$\mathrm{CV}(\%)$ & & 11 & 20 & 52 \\
\hline gl = Grados de libertad; ** Significativo a 0.01 de probabilidad.
\end{tabular}

Los tres tipos de familias presentaron entre 93 y 95 $\%$ de germinación; las líneas $\mathrm{S}_{1}$ exhibieron el porcentaje más bajo (Cuadro 3). La estructura familiar de MH mostró mejor germinación (95\%), mayor poliembrionía (63 $\%)$ y baja frecuencia de plantas anormales (10 \%). Es importante señalar que la endogamia practicada en las familias $S_{1}$ no incrementó la poliembrionía, como podría esperarse si el carácter fuera de herencia simple. La consecuencia teórica de una primera generación de autofecundación es la homocigosidad aleatoria de la mitad de los genes contenidos en un individuo, los cuales pueden incluir genes recesivos deletéreos; en el caso de poblaciones poliembriónicas, algunos de éstos pueden ser responsables de la manifestación de plantas anormales; estos genes deletéreos pueden eliminarse mediante selección en progenies $S_{1}$ (Hallauer y Miranda, 1988). Debido a que con esta estrategia de selección se explota toda la varianza aditiva, se espera que después de un ciclo de selección recurrente disminuya la frecuencia de plantas anormales e incremente la frecuencia de individuos poliembriónicos; por tanto, la selección mediante familias $\mathrm{S}_{1}$ puede ser exitosa en poblaciones poliembriónicas, como lo mencionan Livini et al. (1992) y Weyhrich et al. (1998).

Cuadro 3. Prueba de medias en tres tipos de familias de maíz, para las variables estudiadas.

\begin{tabular}{lccc}
\hline Tipos & $\begin{array}{c}\text { Germinación } \\
(\%)\end{array}$ & $\begin{array}{c}\text { Poliembrionía } \\
(\%)\end{array}$ & $\begin{array}{c}\text { Plántulas anormales } \\
(\%)\end{array}$ \\
\hline $\mathrm{S}_{1}$ & $93 \mathrm{~b}$ & $58 \mathrm{~b}$ & $15 \mathrm{a}$ \\
$\mathrm{HC}$ & $94 \mathrm{a}$ & $59 \mathrm{~b}$ & $16 \mathrm{a}$ \\
$\mathrm{MH}$ & $95 \mathrm{a}$ & $63 \mathrm{a}$ & $10 \mathrm{~b}$ \\
\hline
\end{tabular}

Medias con la misma letra son estadísticamente iguales (Tukey, 0.05). $\mathrm{S}_{1}=$ Primera autofecundación; $\mathrm{HC}=$ Hermanos completos; $\mathrm{MH}=$ Medios hermanos.
Respecto al comportamiento de familias $\mathrm{HC}$ directas y recíprocas, el análisis de varianza (Cuadro 4) para la fuente "sentido de cruza" identificó diferencias significativas $(\mathrm{P}<0.05)$ únicamente en poliembrionía, lo cual significa que hubo efecto recíproco en la población al formar familias de $\mathrm{HC}$, de acuerdo con el sentido del cruzamiento. Esto contribuye favorablemente a la expresión del carácter poliembriónico, de tal manera que el efecto puede aprovecharse al recombinar las familias que lo exhiban; a esto se le puede sumar el buen comportamiento per se de las familias $S_{1}$ formadas en la misma mata donde se generó una familia tipo HC. Lo anterior es un indicio de que la población poliembriónica puede presentar efecto materno, lo cual merece un estudio específico.

Cuadro 4. Cuadrados medios del análisis de varianza para sentido de cruza en una población poliembriónica de maíz.

\begin{tabular}{lcccc}
\hline FV & gl & Germinación & Poliembrionía & $\begin{array}{c}\text { Plántulas } \\
\text { anormales }\end{array}$ \\
\hline $\begin{array}{l}\text { Sentido de } \\
\text { cruza }\end{array}$ & 1 & 3.3 & $525.1 *$ & 53.1 \\
$\begin{array}{l}\text { Error } \\
\text { CV }(\%)\end{array}$ & 74 & 89.2 & 91.6 & 104.9 \\
gl= Grados de libertad; * Significativo a 0.05 de probabilidad.
\end{tabular}

El criterio para definir al grupo de familias HC, directas y recíprocas, fue por el orden en que se realizaron los cruzamientos en campo; es decir, la primera planta receptora de polen fue considerada como directa. El grupo de familias HC directas obtuvo $64 \%$ de poliembrionía, $8 \%$ más que el grupo de familias $\mathrm{HC}$ recíprocas (Cuadro 5); en germinación ambos grupos de familias dieron un resultado aceptable (>90\%).

Cuadro 5. Promedios ${ }^{\dagger}$ en germinación, poliembrionía y plántulas anormales, de cruzas directas y recíprocas de maíz.

\begin{tabular}{lcccc}
\hline $\begin{array}{l}\text { Sentido } \\
\text { de cruza }\end{array}$ & $\begin{array}{c}\text { Núm. de } \\
\text { familias }\end{array}$ & $\begin{array}{c}\text { Germinación } \\
(\%)\end{array}$ & $\begin{array}{c}\text { Poliembrionía } \\
(\%)\end{array}$ & $\begin{array}{c}\text { Plántulas } \\
\text { anormales } \\
(\%)\end{array}$ \\
\hline Directa & 38 & $93 \pm 8$ & $64 \pm 15$ & $14 \pm 10$ \\
Recíproca & 38 & $94 \pm 7$ & $56 \pm 15$ & $16 \pm 11$ \\
\hline
\end{tabular}

${ }^{\dagger}$ Cada promedio se acompaña de su desviación estándar.

Al comparar los dos grupos de familias $\mathrm{S}_{1}$ correspondientes a los grupos de familias $\mathrm{HC}$, directas y recíprocas, no hubo diferencias estadísticas entre ellas para todas las variables bajo estudio. El grupo de familias $\mathrm{HC}$ que no mostró efecto recíproco exhibió un promedio de poliembrionía similar a su correspondiente grupo de familias $\mathrm{S}_{1}$ (56 y $55 \%$, respectivamente). Sin embargo, el grupo de familias $S_{1}$ correspondientes al grupo HC-directas que mostró efecto recíproco, manifestó una reducción significativa de $11 \%$ en poliembrionía (53 y $64 \%$, respectivamente). Esto sugiere que la autofecundación no elevó la poliembrionía; más bien, la expresión del carácter PE parece incrementarse sólo por complementariedad de genes contenidos en algunos individuos de la población 
poliembriónica. Lo anterior parece sugerir que si un individuo, además de mostrar efecto recíproco, se autofecunda, su progenie pudiera expresar en diferente grado el carácter poliembriónico, pero al cruzarse con otra línea de la misma población puede darse la complementariedad de genes, lo que propiciaría un incremento de la expresión del carácter. Si esto fuera el caso, se reafirmaría la efectividad posible del esquema de selección recurrente mediante líneas $S_{1}$ en el mejoramiento de poblaciones poliembriónicas (Cuadro 6).

Cuadro 6. Promedios ${ }^{\dagger}$ de familias de $\mathrm{HC}$ y $S_{1}$ de maíz, en sentido de cruza, para las variables estudiadas.

\begin{tabular}{|c|c|c|c|c|c|c|}
\hline \multirow[b]{2}{*}{$\begin{array}{l}\text { Sentido de } \\
\text { cruza }\end{array}$} & \multicolumn{2}{|c|}{ Germinación } & \multicolumn{2}{|c|}{ Poliembrionía } & \multicolumn{2}{|c|}{$\begin{array}{c}\text { Plántulas } \\
\text { anormales }\end{array}$} \\
\hline & $\mathrm{HC}$ & $\mathrm{S}_{1}$ & $\mathrm{HC}$ & $\mathrm{S}_{1}$ & $\mathrm{HC}$ & $\mathrm{S}_{1}$ \\
\hline Directa & $93 \pm 8$ & $93 \pm 6$ & $64 \pm 1$ & $3 \pm 19$ & $14 \pm 10$ & $16 \pm 12$ \\
\hline Recíproca & $94 \pm 7$ & $95 \pm 4$ & $56 \pm 1$ & $5 \pm 16$ & $16 \pm 11$ & $15 \pm 14$ \\
\hline
\end{tabular}

${ }^{\dagger}$ Cada promedio se acompaña de su desviación estándar.

\section{CONCLUSIONES}

La germinación de los tres tipos de familias fue en general aceptable ( $\geq 93 \%$ ); y fue mejor en las de medios hermanos. Las tres estructuras familiares presentaron una frecuencia poliembriónica mayor que la población base, y las familias de medios hermanos también fueron las que mostraron el porcentaje más alto. La autofecundación no incrementó el carácter poliembriónico, pero fue efectiva para discriminar el mayor número de familias portadoras de genes deletéreos y posibles causantes de la expresión anormal de plántulas. Algunos individuos de la población mostraron efecto recíproco cuando se cruzaron en ambos sentidos para formar familias de hermanos completos, lo que sugiere que hubo efectos maternos en la población bajo estudio.

\section{BIBLIOGRAFÍA}

Espinoza J, M C Vega, E Navarro, G A Burciaga (1998) Poliembrionía en maíces de porte normal y enano. Agron. Mesoam. 9:83-88.

Hallauer A R, J B Miranda (1988) Quantitative Genetics in Maize Breeding. 2nd ed. Iowa State University Press. USA.

Livini C P, A Brandolini, C Lorenzoni, M Motto (1992) Evaluation of three cycles of recurrent selection for yield in a opaque-2 variety of maize. Maydica 37:89-93.

Pesev N, R Petrovic, L J Zecevic, M Milosevic (1976) Study of possibility in raising maize inbred lines with two embryos. Theor. Appl. Gen. 47:197-201.

Pilu R (2000) The twin trait maize. Maize Gen. Coop. News. 74:51.

SAS Institute, Inc (2000) SAS User's Guide. Release 8.1. SAS Institute, Inc. Cary, NC, USA.

Weyhrich R A, K R Lamkey, A R Hallauer (1998) Effective population size and response to $S_{1-}$ progeny selection in the BS11 maize population. Crop Sci. 38:1149-1158. 